This is an Accepted Manuscript of an article published by Taylor \& Francis Group in The Journal of Forensic Psychiatry \& Psychology, published on-line on 24/06/2015, available online: http://www.tandfonline.com/doi/full/10.1080/14789949.2015.1054856

\title{
Recidivist Criminal Behaviour and Executive Functions: a comparative study
}

\author{
Tânia Seruca, ${ }^{\mathrm{a}, \mathrm{b}, \mathrm{c}}$ \& Carlos Fernandes da Silva ${ }^{\mathrm{c}, \mathrm{d}}$
}

\author{
${ }^{a}$ Departamento de Psicologia, Universidade de Évora \\ ${ }^{\mathrm{b}}$ ISPA, Instituto Universitário, Lisboa; \\ ${ }^{\mathrm{c}}$ Departamento de Educação, Universidade de Aveiro \\ ${ }^{\mathrm{d}}$ CINTESIS, R\&D Center of University of Porto
}

Correspondence should be addressed to Tânia Seruca: tseruca@uevora.pt

This work was supported by Fundação Para a Ciência e Tecnologia under grant SFRH / BD / $27450 / 2006$ 


\begin{abstract}
This study sought to analyse the relation between executive functions and criminal recidivism. We assessed a set of cognitive abilities associated with executive functioning in a group of recidivist offenders $(n=19)$, primary offenders $(n=25)$ and non-offenders $(n=30)$. Our results, tested with nonparametric statistics and Monte Carlo method, revealed that there were no executive differences between both groups of offenders but, when compared with non-offenders, the recidivists showed a worse performance in Trail Making Test part B, and the primary offenders presented a significant lower score on Porteus Maze Test Age score. The present study suggests that there can be a different pattern of executive functioning deficits associated with the offenders' criminal record: recidivism may be more related to mental flexibility impairments and primary offenders' antisocial behaviour may be aggravated by planning deficits.
\end{abstract}

Keywords: criminal recidivism; executive functions; neuropsychological assessment; mental flexibility; planning 
Diverse research has revealed that prefrontal brain damages can be associated with antisocial behaviour. There are neuroimaging evidences supporting the relation between prefrontal structural impairments and antisocial behaviour (Blumberg, Stern, Ricketts, Martinez, Asis et al., 1999; Raine, Buchsbaum and Lacasse, 1997; Raine, Meloy, Bihrle, Stoddard, LaCasse and Buchsbaum,1998; Soloff, Meltzer, Becker, Greer and Kellya et al, 2003; Yang, Raine, Lencz, Bihrle, Lacasse and Colleti, 2005), and referring that dorsolateral dysfunction can explain perseverant antisocial behaviours and impaired social functioning that occur throughout the lives of some criminal individuals (Raine and Yang, 2006). The dorsolateral cortex is the brain area more consistently implicated in executive functioning (Fuster, 2000, 2001; Mega \& Cummings, 1994) which plays a critical role in cognitive control by orchestrating thoughts, actions and behaviour according to internal goals (Miller \& Cohen, 2001).

Executive impairments affect both behaviour and cognitive functioning, causing inability to plan sequenced actions (Fuster, 2001; Stuss and Benson, 1984), perseverant behaviours due to the lack of mental flexibility (Goldberg, 2001), difficulty to recall long term memories as well as recently learned information (Mega et al., 1994), and it can lead to behavioural signs such as irritability, excitability, impulsivity, erratic carelessness, and difficulties in shifting an ongoing behaviour (Lezak, Howieson \& Loring, 2004). Such executive deficits have been linked to antisocial behaviour (e. g. Ankarsater, 2006; Brower and Price, 2001; Giancola, 1995; Hoaken, Shaughnessy and Pihl, 2003; Morgan and Lilienfeld, 2000) that consists of unlawful criminal behaviour and leading to incarceration (Morgan and Lilienfeld, 2000) - as it is mentioned by Yang et al., (2005), executive impairments causing impulsivity, disinhibition, poor decision making, and reduction of the individual's sensitivity to environmental cues signalling danger, are factors that can make criminals more prone to be arrested and convicted. For this reason, considering the influence 
that executive functioning has on criminal behaviour, we intended to study executive cognitive functions and criminal recidivism in a group of incarcerated offenders.

Raine (2002) considers that executive impairments in association with specific environmental conditions may cause a chronic, or persistent, pattern of criminal behaviour. In fact, socialization goes beyond its situational aspects and influences the brain's development determining the establishment of permanent neuronal patterns (Cacioppo, Amaral, Blanchard, Cameron, Carter et al., 2007; Joseph, 1999). According to Stiles (2000), in the early stages of development, there are innumerous neuronal connections that are maintained or eliminated based on the environmental inputs: it is during the first decade of life that the neuronal networks that support perception, selective attention, learning, memory, general cognitive ability and personality are set (Joseph, 1999), and in cases where the social environment's inputs are defective, it can cause serious impairments in each aspect of cognitive, emotional or social functioning. Therefore, the family's culture and socialization processes can influence the probability of the individual to develop antisocial behaviour (Kagan, 2004).

According to Farrington (2004), there are individual differences related to a theoretical construct designated as "antisocial tendency" that is rather stable from childhood to adulthood - even though some individuals have changed frequently of environment, the high degree of continuity of antisocial behaviour suggests that the stability depends more on the person that in his environment; even so, it seems that the family's antisocial features can be considered as predictive factors for delinquency due to the fact that some individuals who have a criminal career are usually from problematic families (Farrington, 2004). In this regard, De Bellis (2005) states that the brain's development can be impaired by a complex combination of negligent parental styles, environmental factors - such as malnutrition, domestic violence or lack of educational opportunities - and genetic factors (for mental illness or substance abuse), causing neurocognitive and psychosocial permanent damages due 
to functional deficits in prefrontal and limbic systems causing a lifelong deficit in executive, emotional and behavioural control systems.

Although it is well established that there is a statistically significant relation between antisocial behaviour and executive function deficits (Brower et al., 2001; Morgan et al., 2000), it is still uncertain if the executive functions' deficits are more severe in recidivist offenders (Ross and Hoaken, 2011). Barbosa and Monteiro (2008) have observed that recurrent inmates convicted of nonviolent crimes suffer from executive dysfunction when compared with non-offender controls as they present a significantly poor performance on almost all subtests of the Behavioural Assessment of The Dysexecutive Syndrome. In a different way, Valliant, Freestone, Pottier and Kosmyna (Ross et al., 2011), found no differences between recidivist and non-recidivist offenders on the Wisconsin Card Sorting Test (WCST). In this regard, Ross and Hoaken (2011) compared a group of return inmates with a group of first timers based on the hypothesis that return inmates present more severe and pervasive patterns of executive dysfunction. The authors have observed that return inmates have a worse performance on several executive function variables, indicating deficits in monitoring, strategy formation, associative learning, and response inhibition, as revealed by Non-spatial Conditional Association task, WCST and Go/No-Go task results.

In order to try to understand to what extent the executive impairments are implicated in recidivism, our study aimed to analyse the prefrontal cognitive functions in a small sample of convicted offenders, which included recidivists and primary offenders, comparing them with a group of non-offenders. Our main goal was to determine if there are differences in the executive functioning among recidivist imprisoned offenders (currently serving a second sentence), primary offenders who were serving their first sentence, and individuals with no criminal record. We narrowed the analysis to three neurocognitive functions: mental flexibility - because its deficits can increase the perseveration in an antisocial behaviour 
pattern; planning - mainly due to the fact that it can be linked to behavioural programming impairments; and resistance interference ability - because the inability to control emerging impulses can interfere with the capacity to restrain aggressive impulses. Furthermore, and taking into account the importance of environmental factors in the development of antisocial behaviour, we have also applied a demographic questionnaire to help characterize the subjects criminal background - their family's criminal antecedents and violent behaviours, and also their adolescent peers' delinquent activities.

\section{Method}

\section{Participants}

After giving their written informed consent, 50 Portuguese, White, incarcerated males, and 30 non-offenders, have participated voluntarily in the study - illiterate subjects were not included. Eight offenders were eliminated from further analysis because they had missing data for at least one executive function measure. Hence, 44 offenders were divided into recidivists $(\mathrm{n}=19)$, if they were serving a second sentence, and primary offenders $(\mathrm{n}=$ $25)$ if this was their first official sentence. The recidivists' age ranged from 22 to 57 years $(M$ $=34, S D=9.36, M d n=32)$, with a total years of education between 3 and 16 years $(M=$ $9.05, S D=3.08 ; M d n=9)$; the group of primary offenders' mean age was 32.68 years $(S D=$ $8.26, M d n=30$, range from 21 to 49$)$ with an average of 10.20 years of education $(S D=2.30$, $M d n=9$, range from 6 to 16); and the group of non-offenders had a mean age of 35.67 years $(S D=8.66, M d n=36.50$, range from 22 to 54$)$ and a mean years of education of $10.36(S D=$ 2.56, $M d n=12$, range from 4 to 15$)$. Kruskal-Wallis $H$ test was used to analyse differences between the groups and no significant differences were found in terms of age, $\chi^{2}(2, N=74)$ $=1.588, p=.452$, or years of education, $\chi^{2}(2, \mathrm{~N}=74)=3.173, p=.205$. Additionally, the groups comprised different types of crime: $26.3 \%$ of the recidivists and $40 \%$ of the primary offenders were imprisoned for murder, assault or domestic violence $36.8 \%$ of the recidivists 
and $20 \%$ of the primary offenders committed theft, $26.3 \%$ of the recidivists and $32 \%$ of primary offenders were convicted for drug trafficking, and the smaller proportions of types of crime refer to driving intoxicated or without legal authorization (recidivists $10.5 \%$, primary offenders $8 \%$ ). No significant differences were found between the groups in terms of the type of crime committed, $\chi^{2}(3, \mathrm{~N}=44)=1.910, p=.591$, Cramer's $\mathrm{V}=.208$.

\section{Procedure}

Offenders were recruited from four high-security institutions and approached in person, and each participant gave his written consent after being informed of the voluntary nature of the study. Neuropsychological data were collected in one individual testing session, and all instruments were administered in the exact same order by trained assistants.

Demographic data were collected with a self-reporting questionnaire that was completed by the participants individually. Confidentiality was ensured by removing all personal information from data.

\section{Measures}

Most of the neurocognitive tests selected are reasonably good measures of executive functioning that preferentially activate the frontal cortex and that have been found to differentiate frontal lesions from other brain lesions (Morgan et al., 2000).

Trail Making Test - is a measure of mental flexibility (Kortte, Horner and Windham, 2002) that, according to Morgan and Lilienfeld (2000), is sensitive to frontal lobe damage. The test comprises two parts: Trail Making Test part A (TMT-A) consists in a series of numbers randomly displayed in a page that must be connected in order; the connecting logic of part B is more complex because it requires the subject to alternate from numbers to letters. The test scores are the amount of time needed to complete each part.

Porteus Maze Test (Porteus, 1965, Vineland version) - the subject must draw the correct way 
out of several mazes that are presented in increasing difficulty, and it gives two scores that reflect distinct cognitive features: the test age (TA), that is calculated from the total number of mazes successfully completed, can be considered as an intelligence measure (Porteus, 1965); and the qualitative score (Q score), that is the result of the various types of errors the subject has committed in each maze, can be used as a measure of impulsivity, social adaptation abilities and delinquent behaviour (Brill, 1937; Docter \& Winder, 1954; Porteus, 1965). Overall, Porteus Maze Test is a good measure of executive functions (Krikorian \& Bartok, 1998) that assesses planning and foresight (Lezaket al., 2004), and the Q score can differentiate patients with frontal lesions from patients with other brain injuries (Stuss et al., 1984).

Stroop Interference Score (Portuguese version Fernandes, 2009) - can be used as a measure of response inhibition ability (Lezak et al., 2004) and impulse inhibition (Miyake, Friedman, Emerson, Witzki, Howerter and Wager, 2000; Peterson, Skudlarski, Gatenby, Zhang, Anderson et al., 1999). The subject must ignore the written name of several colours and name the colour in which those words are printed; the pure interference score was calculated based on the Color-Word and predicted Color-Word scores (Golden, 1978).

Demographic self-reporting questionnaire - the demographic questionnaire included several closed questions to describe the criminal factors that were present in the subject's family and social relations during his childhood and adolescence.

\section{Statistical Testing}

The demographic differences concerning the participants' personal and familiar history of antisocial behaviour were studied with Pearson's chi-square test for Independence $\left(\chi^{2}\right)$ and with Fisher's exact test (used in the cases were at least $20 \%$ of the cells expected count was less than 5) and are also presented in percentages of affirmative answers. Cramer's 
V was used as a measure of effect size and interpreted according to Cohen guidelines for $2 d f$ : between .07 and .21 is considered a small effect; between .21 and .35 a medium effect; and values greater than .35 indicate a large effect size (Reid, 2013).

Most of the neurocognitive results (as well as the groups' years of education) did not present a normal distribution and were highly skewed (Table 2). For this reason, and also taking into account the fact that the samples are small and unequal, a non-parametric approach was used. Therefore, the executive functions' comparisons between the three groups were based on the non-parametric Kruskal-Wallis test and the subsequent post-hoc pairwise comparisons between the recidivists, primary offenders and normal controls, were based on the Mann-Whitney $U$-tests with Monte Carlo method to compensate the small sample size and to control for Type I error - exact $p$-value was computed based on 10,000 random permutations and is reported with $99 \%$ confidence intervals. Effect size was calculated with Mann-Whitney $Z$ value (Fritz, Morris and Richler, 2012) and interpreted according to Cohen's $r$ convention: small $\geq .01$, medium $\geq .30$ and large $\geq 50$ (Fritz et al., 2012; Garamszegi, 2006). Results were considered statistically significant at the .05 level (two-tailed).

\section{Results}

\section{Participant's Criminal Background}

The statistical study shows that there are significant differences, with medium to large effect sizes, between the research groups in terms of their history of family and personal antisocial behaviours, and that criminal recidivists have the higher percentages of affirmative answers in most items (Table 1). The differences emerged mainly in terms of childhood familiar environment: recidivists are more likely to have had a childhood's close relative who took drugs $(31.3 \%$ recidivists, $0 \%$ primary and non-offenders; $p=.001$, Fisher's exact test, 
Cramer's $\mathrm{V}=.509)$ or a close relative imprisoned $(31.3 \%$ recidivists, 16.7 primary, and 3.3 $\%$ non-offenders; $p=.028$, Fisher's exact test, Cramer's V $=.312$ ). Also, the recidivists present the larger percentage of participants (18.8\%) who have been beaten until unconscious by family members during childhood $(4.3 \%$ of the primary offenders also mention that fact, while none of the non-offenders reports it; $p=.031$, Fisher's exact test, Cramer's V $=.314$ ). [Table 1 near here]

In terms of adolescent antisocial behaviour, there are no significant differences between the groups, except for the fact that half of the recidivist group had at least one teenage friend who was involved in antisocial activities, such as alcohol or drug abuse, small thefts, or street fights (recidivists $50.0 \%$, primary $17.4 \%$, and non-offenders $10.3 \% ; \chi^{2}(2, \mathrm{~N}$ $=74)=9.871, p=.008$, Cramer's $\mathrm{V}=.381)$. Regarding the subjects' delinquent behaviours during adolescence, it can be observed that the larger percentage of alcohol consumers belongs to the group of recidivists (75\%), followed by the non-offenders (with $72.4 \%$ ) and by the group of primary offenders (43\%), and half of the recidivists state that they had consumed soft drugs during adolescence (50\% recidivists, $30.4 \%$ primary offenders, and $24.1 \%$ nonoffenders), both with no significant differences associated. Additionally, the recidivists had the higher percentage of affirmative answers (75\%) to the question whether if they were involved in street fights or brawls during adolescence, while the groups of primary offenders and non-offenders showed a very similar percentage (39.1.\% and $41.4 \%$ respectively).

\section{Executive Functioning}

Neuropsychological measures were examined for normality using Shapiro-Wilk test (Table 2) and it was found that TMT-B (primary offenders $p=.013$, non-offenders $p=.003$ ), Porteus Maze Q score (primary offenders $p=.002$ ) and Stroop Interference score (recidivists group $p=.012$ ) were not normally distributed, and for this reason a non-parametric approach 
was preferred. The Kruskal-Wallis $H$ test (Table 3 ) revealed a statistically significant difference between the groups in TMT-B score $\chi^{2}(2, \mathrm{~N}=74)=7.114, p=.029$, and further pairwise comparisons were made using Monte Carlo-Mann-Whitney $U$ tests (Table 3). The post-hoc analysis showed no statistical differences between the two groups of offenders in any of the neurocognitive measures, however it revealed that the primary offenders have statistically significant lower scores with medium effect size $(U=235.0, p=.016$, Monte Carlo 99\% CI .012-.019, $r=-.320)$ on Porteus Test Age score $(M d n=16.0, I Q R=3.5)$ than non-offenders $(M d n=17.5, I Q R=2.7)($ Table 2$)$, and that the recidivists present a significant worse performance $(U=151.0, p=.005$, Monte Carlo 99\% CI .003-.007, $r=-.393)$ on TMT$\mathrm{B}(M d n=88.0, I Q R=48.0)$ than the non-offenders $(M d n=65.5, I Q R=28.0)($ Table 2$)$. [Table 2 and Table 3 near here]

\section{Discussion}

This study was based on the assumption that criminal recidivism can be related to specific executive functioning impairments, and that such impairments could lead to executive differences among recidivists, primary offenders and non-offenders. This hypothesis was partially confirmed because no statistically significant differences were observed between both groups of offenders in any of the neuropsychological measures, but two significantly different patterns of executive impairments have emerged from the comparisons of each group of offenders with the non-offenders participants: the recidivists presented a poor performance in TMT-B ; and the primary offenders showed a worse Porteus TA score. Given these results, we can suggest that the executive functioning of criminal recidivists may be characterized by poor mental flexibility skills, whereas the primary offenders' main executive impairment appears to be restricted to planning abilities.

Our data suggests that recidivist antisocial behaviour may be aggravated by mental flexibility impairments, often implicated in misinterpretations of situational cues that 
incapacitate these subjects to see things in a different perspective (Goldberg, 2001). AlcazárCorcóles, Verdejo-García, Bouso-Saiz, \& Bezos-Saldaña (2010) consider that impaired mental flexibility skills can seriously deteriorate the individual's social abilities needed to find alternative solutions to conflict situations. Although the authors were referring specifically to aggressive behaviours, the cognitive rigidity that restrains these individuals from easily shifting from one thought or behaviour to another might be extended to other situations. Mental flexibility is essential to the normal functioning of other executive abilities (McDonald, Flashman and Saykin, 2002) and lacking intact executive skills can be related to recidivism because offenders are not able to deal with complexity and, as such, criminal behaviour appears as the default response to difficult situations involving, for instance, financial strain or aggressive interpersonal encounters (Hancock, Tapscott and Hoaken, 2010; Ross and Hoaken, 2011). Taking this into consideration, we suggest that impaired mental flexibility skills can increase the perseverance in rigid criminal behavioural patterns despite the type of offense committed.

The primary offenders' neurocognitive results may indicate that the executive impairment of this group is related to defective foresight and planning abilities given their Porteus TA score (Mack and Patterson, 1995; Porteus, 1965) and with an inability to delay gratification in immediate and practical situations (Riddle and Roberts, 1977). It must be taken into account that TA score does not distinguish delinquents from nondelinquents, and its relation with recidivism is unclear (Riddle et al., 1977), but according to Porteus (1965), the mazes' score can be influenced by overconfidence, impulsivity or neglect, which are features that can reflect a careless way of life and that can affect these individual's social interactions.

No significant differences were found in Stroop score, a measure sensitive to impulsivity and inhibition which are traits frequently assessed in offenders' population but 
with inconsistent results. Stroop interference score is a prepotent response inhibition measure that correlates with tests of attention, working memory, conceptual ability and speed of processing (Strauss et al., 2006). In a general way, large interference scores indicate poor selective attention and excessive distraction from irrelevant information, and have been associated with many syndromes of disinhibition related to psychopathy (Hiatt, Schmitt and Newman, 2004). Nonetheless, a number of studies have found that psychopathic individuals do not have a global impairment in response inhibition assessed with Stroop (De Brito and Hodgins, 2009; Hiatt et al., 2004; Pham, Vanderstukken, Philippot and Vanderlinden, 2003).

Conversely, other research has studied the relationship between inhibition abilities and antisocial behaviour with different neurocognitive instruments: Meijers, Harte, Jonker and Meynen (2015) have reviewed some studies comparing the executive functions between violent and non-violent offenders, and concluded that both types of offenders present inhibition deficits (not assessed with Stroop), except those that have a story of premeditated, thus non-impulsive, violent crimes; Hancock et al. (2010), have observed that offenders who have committed a large number of violent offences performed worse in measures sensitive to impulsivity, measures of concept formation, and cognitive flexibility, or were less likely to correct errors made on the switching condition of the CWIT (a test similar to Stroop) - the authors find difficult to explain this last observation because the offenders as a group committed a large number of corrected errors, but they consider that it may indicate that offenders with higher rates of violent offences may lack the ability to monitor their behaviour; and regarding a comparison between recidivists and first timers (despite the violence of the crime), Ross and Hoaken (2011) found that return inmates show executive deficits in response monitoring, strategy formation, associative learning, and response inhibition (assessed with Go/No-Go task).

These different results concerning inhibition skills of adult inmates may be explained 
by the heterogeneity of the criminal factors analysed (psychopathy, violent offending, or recidivism) or, as it is mentioned by Hancock et al. (2010), because the different measures used may not assess the same abilities or share the same psychometric properties.

Nevertheless, the fact that none of our research groups had showed an impaired Stroop Interference score may suggest that their antisocial behaviour rates might not influenced by response inhibition or selective attention deficits. Moreover, the Stroop Interference score taken together with TMT-A and Porteus Q scores support the fact that there is not an overall impairment of the executive functions in our sample of offenders and that the individuals do not have a tendency to perform poorly on every neuropsychological measure.

Our findings are consistent with previous research that has observed that there are executive functioning differences between recidivists and non-offenders (Barbosa et al., 2008) and that offenders with least frequent thefts present lower TMT-B scores while those with most frequent thefts show higher, thus worse, TMT-B scores (Barker, Séguin and White, 2007), as well as with studies that did not find executive differences between recidivists and non-recidivists (Valliant and colleagues cited by Ross et al., 2011). Indeed, we were not able to find any differences between recidivists and primary inmates as those reported by Hancock et al. (2010) that observed that offenders who committed a large number of crimes present an impaired performance on prepotent verbal responses inhibition, concept formation and cognitive flexibility measures, or by Ross et al. (2011) that found that return inmates show executive deficits in response monitoring, strategy formulation, associative learning and response inhibition.

Additionally, some environmental factors usually implicated in the development of antisocial behaviour were also taken into account and, for this reason, a self-reporting demographic questionnaire was applied to help characterize the subjects criminal background - their family criminal antecedents and violent behaviours, as well as their previous 
involvement in delinquent activities. Significant differences were found between the groups, being the recidivists the group with the higher percentage of cases that reported to have had a childhood family member who had a problem of drug abuse, who had a close relative imprisoned during childhood, or who were physically attacked until being unconscious. The recidivists also had a number of friends in their adolescent social network involved in delinquent behaviours. In fact, the study of the antisocial demographic features can mean that the development of a persistent pattern of antisocial activities throughout these subjects lives may be somehow related to the presence of antisocial factors in their early development's environment.

These results are in harmony with studies that relate lifelong persistent antisocial behaviours to the environment where the individual was raised and the importance of his early relations. For instance, Moffitt considers that lifelong antisocial behaviour can be the result of cumulative interactions between criminogenic environments and the children's neuropsychological vulnerabilities (Alink and Engeland, 2013), or Farrington (2004), refers that antisocial families generate persistent offenders, being factors such as family criminality, poverty, and inadequate parental care, predictors of delinquency in childhood. Actually, as it is reported by Cacioppo et al. (2007), the human mind is the result of the combination of biological, social and psychological factors, and the early development of the brain consists in eliminating a series of neuronal connections and preserving others, depending the selection of neural networks on the social environment inputs (Stiles, 2000). Thus, it must be borne in mind that specific genes may also determine structural and functional brain impairment that predispose to antisocial behaviour (Raine, 2008) and that antisocial behaviour can occur, or be exacerbated, as a consequence of the interaction of personal factors and situational circumstances (Lahey \& Waldman, 2003).

Taking this data into account, it can be assumed that some cases of criminal 
recidivism may be due to the fact that the subjects were raised in an antisocial environment (Farrington, 2004). But, if on one hand the insertion in a criminal environment can have an indirect influence on the neural networks responsible for a stable antisocial tendency, on the other hand living in a violent environment can have a direct influence on brain functioning, because it increases the frequency of physical aggressions (either in street fighting's or as being a victim of aggressions) that can cause direct damage to the brain, specially to the frontal lobes due to its anatomical localization (Raine et al., 1991). Nevertheless, our aim was neither to determine the social causes of recidivism, nor to establish a relation between antisocial environments and executive functioning, but we consider that the hypothetical relation between the milieu and the brain must be further studied through the proper research means, by analyzing the influence of the socialization and learning processes in the definition of the neuronal networks for social adaptation.

There are some limitations to this study that must be acknowledged. Firstly, our sample size is not large enough to generalize the results and, although being sufficient to reveal significant executive functioning differences between the groups, in such cases a larger sample would possibly allow other differences to emerge (Ross et al., 2011). Furthermore, despite the fact that no differences were observed in terms of type of crime between the groups of offenders, controlling the sample's criminal heterogeneity as well as the frequency and severity of the criminal behaviour could have allowed a better exploration of the executive differences analysis. There are also limitations related to the use of a self-reporting questionnaire to assess previous antisocial behaviour, namely the fact that the items hardly cover all the antisocial behaviour that may have naturally occurred, and the individual's answers may not be accurate due to recall bias or social desirability bias (Fonseca and Simões, 2004). We consider that future research should be conducted to explore the relation between criminal recidivism and executive functions using follow-up studies, larger sample 
sizes to control for the type of crime and recidivism rates, and a more diverse range of executive functions measures, as well as it should also broaden the scope of possible analysis to cognitive and psychiatric factors.

A further limitation of our study is the absence of measures to determine the prevalence of traumatic brain injury and psychiatric disorders. A large proportion of prisoners meet the criteria for a current or lifelong psychiatric disorder (Gunter et al., 2008), and most of inmates report a traumatic brain injury over their lifetime (Slaughter, Fann and Ehde, 2003). However, the assessment of such factors is a complex task and may lead to imprecise information because if, on the one hand, the study of past traumatic brain injury must gather extensive information on the circumstances of the incident and in some cases, due to memory impairments, the subjects may find difficult to recall the extent of past injuries (Slaughter et al., 2003); on the other hand, psychological testing can be considered suspicious by forensic populations (Hancock et al., 2010) that consist in a large number of Antisocial Personality cases characterized by being dishonest and who may not give genuine answers to such assessments (Poythress, Edens, Skeem, Lilienfeld, Douglas et al., 2010). Thus, we consider that the relation between recidivism, brain injury history and mental health history should be assessed with the appropriate techniques, as it is mentioned by Slaughter et al. (2003), corroborating self-reporting inventories with medical records.

Also, the findings about the relation between neurocognitive impairments, head injury, and psychiatric disorders in antisocial groups is not clear, and for this reason a thorough psychiatric examination should also be included in future studies in order to provide further information about it. For instance, Slaughter et al. (2003) suggest that more recent traumatic brain injury can be related to cognitive impairments and psychiatric disorders, but Raine, Moffit, Caspi, Loeber, Stouthamer-Loeber \& Lynam (2005) have observed that neurocognitive impairments in antisocial groups were neither attributable to environmental 
processes such as abuse, psychosocial adversity or history of head injury, nor to Attention Deficit Hyperactivity Disorder (ADHD). In fact, ADHD accounts for a large proportion of offenders, and those with persisting symptoms have a younger onset of offending and a higher rate of recidivism (Young and Thome, 2011). But it must be borne in mind that despite being often associated with impairments in several executive functions, executive deficits are not the exclusive cause for all ADHD cases (Willcutt, Doyle, Nigg, Faraone and Pennington, 2005), neither the executive function deficits in offenders' samples are attributable to ADHD (Giancola, Mezzich and Tarter, 1998; Raine et al., 2005). Nevertheless, given the prevalence of cases of ADHD in criminal populations, the small but significant number of offenders with autism-spectrum disorder, its relationship with antisocial behaviour, and executive functions (Dein and Woodbury-Smith, 2010; Jurado and Rosseli, 2007; Murphy, 2010), we find that future research should screen for such disorders in order to understand its importance in criminal recidivism.

Finally, the assessment of general cognitive ability would also have provided additional information about the executive deficits found but, besides falling outside our study's scope, there are several works that consider that this relation is not yet clearly determined. According to Friedman, Miyake, Corley, Young, DeFries and Hewitt (2006), intelligence relates differently with different executive functions - the executive function of updating and monitoring of working memory is closely related to intelligence, while shifting between tasks or mental sets, and inhibiting dominant or prepotent responses present weak to nonexistent relations with intelligence. Krikorian et al. (1998) found weak associations between maze performance and IQ, and mention a study by Duncan that observed that executive function is related to low IQ in nonclinical samples and that very low IQ might predict significant executive function impairment. The meta-analytic review performed by Morgan et al. (2000) revealed that antisocial individuals performed worse on measures of EF 
despite controlling for intelligence and, more recently, Tuominen, et al. (2014), considered that the relationship between executive function skills and performance in IQ tests is complex and that IQ could not explain all the executive function deficits of the offenders in their sample.

Despite the limitations, our results suggest that there are executive differences between the groups of offenders: the recidivists, who have more than one conviction in their criminal record, present a mental flexibility impairment; while the primary offenders, who were serving their first sentence, show a planning deficit. Moreover, we were also able to observe that the group of recidivists have a worse family criminal background, in comparison with the remaining groups. These data are consistent with previous studies' suggesting that recidivists' executive impairments are founded in mental flexibility deficits Barker et al., 2007; Hancock et al., 2010), that can cause perseveration in a dysfunctional lifestyle (Raine and Yang, 2006), and that can be originated by an early insertion in an antisocial environment. However, the relationship between social environment and development of executive deficits needs further research to be fully understood, for instance through longitudinal research on how the development of executive functions occurs under the influence of different types of environment. Finally, the identification of the executive deficits related to recidivism versus one only criminal offense, can be quite useful in the design of specific rehabilitation programmes concerning criminal behaviour. 


\section{References}

Alcázar-Córcoles, M. A., Verdejo-García, A., Bouso-Saiz, J. C. \& Bezos-Saldaña L. (2010). Neuropsicología de la agresión impulsiva. Revista de Neurologia, 50, 291-9.

Alink, L. R. A., \& Egeland, B. (2013). The roles of antisocial history and emerging adulthood developmental adaptation in predicting adult antisocial behavior. Aggressive Behavior, 39, 131-140.

Anckarsater, H. (2006) Central nervous changes in social dysfunction: Autism, aggression, and psychopathy. Brain Research Bulletin, 69 (3), 259-265.

Barbosa, M. F. S. \& Monteiro, L. M. C. (2008). Recurrent Criminal Behavior and Executive Dysfunction. The Spanish Journal of Psychology. 11 (1), 259-265.

Barker, E. D., Séguin, J. R., White, H. R., Bates, M. E., Lacourse, E., Carbonneau, R \& Tremblay, R. E. (2007). Developmental trajectories of male physical violence and theft: Relations to Neurocognitive Performance. Archives of General Psychiatry, 64 (5), $592-599$.

Brill, M. (1937). The validity of the Porteus Maze Test. Journal of Educational Psychology, 28 (7), 481-493.

Brower, M. C. \& Price, B. H. (2001). Neuropsychiatry of frontal lobe dysfunction in violent and criminal behaviour: a critical review. Journal of Neurology, Neurosurgery \& Psychiatry, 71, 720-726

Cacioppo, J. T., Amaral, D. G., Blanchard, J. J. ,Cameron, J. L., Carter, C. S., Crews, D., Fiske, S., Heatherton, T., Johnson, M. K., Kozak, M. J., Levenson, R. W., Lord, C., Miller, E. K., Ochsner, K., Raichle, M. E., Shea, M. T., Taylor, S. E., Young, L. J. \& Quinn, K. J. (2007). Social Neuroscience: Progress and Implications for Mental 
Health. Perspectives on Psychological Science, 2, 99-123.

Dias, J. F. \& Andrade, M. C. (1997). Criminologia: O Homem Delinquente e a Sociedade Criminógena. Coimbra Editora.

De Bellis, M. D. (2005). The Psychobiology of Neglect. Child Maltreatment, 10, 150-172.

De Brito, S. A. \& Hodgins, S. (2009). Executive functions of persistent violent offenders: A critical review of the literature. In S. Hodgins, E. Viding \& A. Plodowski (Eds.), Persistent violent offenders: Neurobiology and rehabilitation. Oxford: Oxford University Press.

Docter, R. F.; Winder, C. L. (1954). Delinquent vs nondelinquent performance on the Porteus Qualitative Maze Test. Journal of Consulting Psychology. 18 (1), 71-73.

Dias, J. F. \& Andrade, M. C. (1997). Criminologia: O Homem Delinquente e a Sociedade Criminógena. Coimbra Editora.

Farrington, D. P. (2004). O Estudo de Desenvolvimento da Delinquência de Cambridge: principais resultados dos primeiros 40 anos [Key results from the first forty years of the Cambridge Study in Delinquent Development (S. M. Nogueira, A. C. Fonseca, and M. Oliveira, Trans.)] . In Fonseca, A. C. (Eds.) Comportamento antisocial e crime: da infância à idade adulta (pp.1-10). Coimbra: Almedina.

Fernandes, S. (2009). Adaptación del test de Colores y Palabras de Stroop en una Muestra Portuguesa - Influencia de la Reserva Cognitiva en la Función Ejecutiva de Sujetos Sanos y con Enfermedad Tipo Alzheimer de Inicio Tardio [Adaptation of the Stroop Color and Word Test to a Portuguese sample: The influence of the cognitive reserve on the executive functions of patients with early-onset Alzheimer's disease]. Doctoral Thesis presented in Universidad de Salamanca, Salamanca.

Fonseca, A. C. \& Simões, M. C. T. (2004). Comportamento Antisocial: Técnicas e 
Instrumentos de Avaliação [Antisocial behavior: Assessment instruments and techniques]. In Fonseca, A. C. (Eds.) Comportamento antisocial e crime: da infância à idade adulta (pp.1-10). Coimbra: Almedina.

Friedman, N. P., Miyake, A., Corley, R. P., Young, S. E., DeFries, J. C. \& Hewitt, J. K. (2006). Not All Executive Functions Are Related to Intelligence. Psychological Science, 17(2): 172-179.

Fritz, C. O., Morris, P. E. \& Richler, J. J. (2012). Effect size estimates: current use, calculations, and interpretation. Journal of Experimental Psychology: General, 141 (1), 2-18.

Fuster, J. (2000). Executive frontal functions. Experimental Brain Research, 133, 66-70

Fuster, J. (2001). The prefrontal cortex - an update: Time is of the essence. Neuron, 30, 319333.

Garamszegi, L. Z. (2006). Comparing effect sizes across variables: generalization without the need for Bonferroni correction. Behavioral Ecology 17(4), 682-687.

Giancola, P. (1995). Evidence for Dorsolateral and Orbital Prefrontal Cortical Involvement in the Expression of Aggressive Behavior. Aggressive Behavior, 21, 431-450.

Giancola, P. R., Mezzich, A. C. \& Tarter, R. E. (1998). Executive Cognitive Functioning, Temperament, and Antisocial Behavior in Conduct-Disordered Adolescent Females. Journal of Abnormal Psychology 107(4): 629-641.

Goldberg, E. (2001). The Executive Brain: frontal lobes and the civilized mind. New York: Oxford University Press.

Golden, C. J. (1978). Stroop color and word test manual. Chicago: Stoelting Co.

Hancock, M., Tapscott, J. L. and Hoaken, N. S. (2010). Role of Executive Dysfunction in 
Predicting Frequency and Severity of Violence. Aggressive Behavior, 36, 338-349.

Hiatt, K. D., Schmitt, W. A. and Newman, J. P. (2004). Stroop Tasks Reveal Abnormal Selective Attention Among Psychopathic Offenders. Neuropsychology 18(1): 50-59.

Hoaken, P. N. S., Shaughnessy, V. K. \& Pihl, R.O. (2003). Executive cognitive functioning and aggression: Is it an issue of impulsivity? Aggressive Behavior, 29, 15-30.

Joseph, R. (1999). Environmental Influences on Neural Plasticity, the Limbic System, Emotional Development and Attachment: A Review. Child Psychiatry and Human Development, 29(3), 189-208.

Jurado, M. B. \& Rosselli, M. (2007). The Elusive Nature of Executive Functions: A Review of our Current Understanding. Neuropsychol Rev 17: 213-233

Kagan, J. (2004). Comportamento anti-social: contributos culturais, vivenciais e temperamentais [Antisocial behaviour: cultural, experiential and temperamental contributions. (L. N. Lima, Trans)]. In Fonseca, A. C. (Eds.) Comportamento antisocial e crime: da infância à idade adulta (pp.1-10). Coimbra: Almedina.

Kortte, K. B., Horner, M. D., \& Windham, W. K. (2002). The trail making test, part B: cognitive flexibility or ability to maintain set? Applied neuropsychology. 9 (2), 106109.

Krikorian, R., \& Bartok, J. A. (1998). Developmental data for The Porteus Maze Test. The Clinical Neuropsychologist, 12 (3), 305-310.

Lahey, B. B. \& Waldman, I. W. (2004). Predisposição para problemas do comportamento na infância e na adolescência: análise de um modelo desenvolvimentista [A developmental propensity model of the origins of conduct problems during childhood and adolescence. (T. S. Machado, Trans.]. In Fonseca, A. C. (Eds.) Comportamento anti-social e crime: 
da infância à idade adulta (pp.161-214). Coimbra: Almedina.

Lezak, M. D., Howieson, D. B. \& Loring, D. (2004). Neuropsychological Assessment (4th edition). New York: Oxford University Press.

Mack, J. L. \& Patterson, M. B. (1995). Executive Dysfunction and Alzheimer's Disease:

Performance on a Test of Planning Ability, the Porteus Maze Test. Neuropsychology, 9 (4), 556-564.

McDonald, B. C., Flashman, L. A., and Saykin, J. (2002). Executive dysfunction following traumatic brain injury: Neural substrates and treatment strategies. NeuroRehabilitation, 17: $333-344$

Mega, M. S. \& Cummings, J. L. (1994). Frontal subcortical circuits and neuropsychiatric disorders. The Journal of Neuropsychiatry and Clinical Neurosciences, 6, 358-370.

Meijers, J., Harte, J. M., Jonker, F. A. and Meynen, G. (2015). Prison Brain? Executive Dysfunction in Prisoners. Frontiers in Psychology 6(43): 1-6.

Miller, E. K. \& Cohen, J. D. (2001). An integrative theory of prefrontal córtex funcion. Annu. Rev. Neurosci., 24, 167-202.

Miyake, A., Friedman, N. P., Emerson, M. J., Witzki, A. H., Howerter, A., Wager, T. D. (2000). The Unity and Diversity of Executive Functions and Their Contributions to Complex "Frontal Lobe" Tasks: A Latent Variable Analysis. Cognitive Psychology. 41 (1), 49-100.

Morgan, A. \& Lilienfeld, S. (2000). A meta-analytic review of the relation between antisocial behavior and neuropsychological measures of executive function. Clinical Psychology Review, 20 (1), 113-136.

Murphy, D. (2010). Understanding offenders with autism-spectrum disorders: what can 
forensic services do? Commentary on...Asperger Syndrome and Criminal Behaviour. Advances in psychiatric treatment, 16: 44-48.

Peterson, B. S., Skudlarski, P., Gatenby, J. C., Zhang, H., Anderson, A. W. and Gore, J. C. (1999). An fMRI Study of Stroop Word-Color Interference: Evidence for Cingulate Subregions Subserving Multiple Distributed Attentional Systems. Biol Psychiatry, (45), $1237-1258$

Pham, T. H., Vanderstukken, O., Philippot, P. \& Vanderlinden, M. (2003). Selective Attention and Executive Functions: Deficits Among Criminal Psychopaths. Aggressive Behavior, 29: 393-405

Porteus, S. D. (1965). Manuel du Test des Labyrinthes de Porteus [Porteus maze test manual]. Paris: Centre de Psychologie Appliquée.

Poythress, N. G., Edens, J. F., Skeem, J. L., Lilienfeld, S. O., Douglas, K. S., Frick, P. J., Patrick, C. J., Epstein, M. \& Wang, T. (2010). Identifying Subtypes Among Offenders With Antisocial Personality Disorder: A Cluster-Analytic Study. Journal of Abnormal Psychology 119 (2), $389-400$

Raine, A. (2008). From Genes to Brain to Antisocial Behavior. Current Directions in Psychological Science, 17 (5), 323-328.

Raine, A. (2002). Biosocial Studies of Antisocial and Violent Behavior in Children and Adults: A Review. Journal of Abnormal Child Psychology, 30(4), 311-326

Raine, A., Buchsbaum, M., and Lacasse, L. (1997). Brain Abnormalities in Murderers Indicated by Positron Emission Tomography. BIOL PSYCHIATRY, 42, 495-508.

Raine, A., Meloy, J. R., Bihrle, S., Stoddard, J., LaCasse, L., Buchsbaum, M. S. (1998). Reduced Prefrontal and Increased Subcortical Brain Functioning Assessed Using 
Positron Emission Tomography in Predatory and Affective Murderers. Behavioral Sciences and the Law, 16, 319-332.

Raine, A., Moffit, T. E., Caspi, A., Loeber, R., Stouthamer-Loeber, M., \& Lynam, D. (2005). Neurocognitive Impairments in Boys on the Life-Course Persistent Antisocial Path. Journal of Abnormal Psychology 114(1): 38-49.

Raine, A. \& Scerbo, A. (1991). Biological theories of violence. In Milner, J. S. (ed.), Neuropsychology of Aggression (pp. 1-25). Kluwer Academic Publishers, Boston.

Raine, A. \& Yang, Y. (2006). Neural foundations to moral reasoning and antisocial behavior. SCAN, 1, 203-213

Reid, H. M. (2013). Introduction to Statistics: Fundamental Concepts and Procedures of Data Analysis. SAGE Publications.

Riddle, M. \& Roberts, A. H. (1977). Delinquency, Delay of Gratification, Recidivism, and the Porteus Maze Tests. Psychological Bulletin, 84 (3), 417-425

Ross. E. H. and Hoaken, P. N. S. (2011). Executive Cognitive Functioning Abilities of Male First Time and Return Canadian Federal Inmates. Canadian Journal of Criminology \& Criminal Justice, 377-403.

Slaughter, B., Fann, J. R. \& Ehde, D. (2003). Traumatic brain injury in a county jail population: prevalence, neuropsychological functioning and psychiatric disorders. Brain Injury 17(9): 731-741.

Soloff, P. H., Meltzer, C. C., Becker, C., Greer, P. J., Kellya, T. M., Constantinea, D. (2003). Impulsivity and prefrontal hypometabolism in borderline personality disorder. Psychiatry Research: Neuroimaging, 123, 153-163.

Stiles, J. (2000). Neural Plasticity and Cognitive Development. Developmental 
Neuropsychology, 18 (2), 237-272

Strauss, E., Sherman, E. M. S. and Spreen, O. (2006). A Compendium of Neuropsychological Tests: Administration, Norms, and Commentary. New York: Oxford University Press.

Stuss, D. T. \& Benson, D. F. (1984). Neuropsychological studies of the frontal lobes. Psychological Bulletin, 95 (1), 3-28.

Willcutt, E. G., Doyle, A. E., Nigg, J. T., Faraone, S. V. and Pennington, B. F. (2005). Validity of the Executive Function Theory of Attention-Deficit/Hyperactivity Disorder: A Meta-Analytic Review. Biol Psychiatry 57: 1336-1346

Yang, Y., Raine, A., Lencz, T., Bihrle, S., Lacasse, L. \& Colletti, P. (2005). Volume Reduction in Prefrontal Gray Matter in Unsuccessful Criminal Psychopaths. Biological Psychiatry, 57, 1103-1108.

Young, S. \& Thome, J. (2011). ADHD and offenders. The World Journal of Biological Psychiatry, 12(S1): 124-128. 
Table 1 - Participants' Background Characteristics: Familiar and Personal Antisocial Factors

\begin{tabular}{|c|c|c|c|c|c|c|}
\hline & recidivists & primary & $\begin{array}{c}\text { non- } \\
\text { offenders }\end{array}$ & & & \\
\hline & $\%$ & $\%$ & $\%$ & $\chi^{2}$ & $p$ & $\mathrm{~V}$ \\
\hline $\begin{array}{l}\text { abuse of alcohol in the } \\
\text { family }\end{array}$ & 31.3 & 20.8 & 20 & .834 & .659 & .109 \\
\hline $\begin{array}{l}\text { abuse of drugs in the } \\
\text { family }\end{array}$ & 31.3 & 0.0 & 0.0 & $12.346^{1)}$ & $.001^{* *}$ & .509 \\
\hline $\begin{array}{l}\text { close family member } \\
\text { imprisoned }\end{array}$ & 31.3 & 16.7 & 3.3 & $6.725^{1)}$ & $.028^{*}$ & .312 \\
\hline $\begin{array}{l}\text { witnessed physical } \\
\text { domestic violence } \\
\text { (during childhood) }\end{array}$ & 37.5 & 29.2 & 17,2 & 2.376 & .305 & .186 \\
\hline $\begin{array}{l}\text { subject was beaten } \\
\text { (during childhood) }\end{array}$ & 50.0 & 37.5 & 41,4 & .624 & .732 & .095 \\
\hline $\begin{array}{l}\text { subject was beaten until } \\
\text { unconscious (during } \\
\text { childhood) }\end{array}$ & 18.8 & 4.3 & 0.0 & $5.350^{1)}$ & $.031 *$ & .314 \\
\hline $\begin{array}{l}\text { teenage friends' } \\
\text { antisocial behaviour }\end{array}$ & 50.0 & 17.4 & 10.3 & 9.871 & $.008 * *$ & .381 \\
\hline $\begin{array}{l}\text { alcohol use (during } \\
\text { adolescence) }\end{array}$ & 75.0 & 43.0 & 72.4 & 5.865 & .053 & .294 \\
\hline $\begin{array}{l}\text { soft drugs use } \\
\text { (during adolescence) }\end{array}$ & 50.0 & 30.4 & 24,1 & 3.210 & .201 & .217 \\
\hline $\begin{array}{l}\text { engagement in street } \\
\text { fights or brawls (during } \\
\text { adolescence) }\end{array}$ & 75.0 & 39.1 & 41,4 & 5.895 & .052 & .294 \\
\hline
\end{tabular}

1) Fisher exact test (more than $20 \%$ of the cells expected count were less than 5);

$* p<.05 ; * * p<.01$ 
Table 2 - Median, Interquartile Range, Skewness $(S k)$ and Shapiro-Wilk Test of Normality $p$ value $(S W)$ For Executive Measures For All Research Groups

\begin{tabular}{|c|c|c|c|c|c|c|c|c|c|c|c|c|}
\hline & \multicolumn{4}{|c|}{ Recidivists $(\mathrm{n}=19)$} & \multicolumn{4}{|c|}{ Primary $(n=25)$} & \multicolumn{4}{|c|}{ Non-offenders $(\mathrm{n}=30)$} \\
\hline & $M d n$ & $I Q R$ & $S k$ & $S W$ & $M d n$ & $I Q R$ & $S k$ & $S W$ & $M d n$ & $I Q R$ & $S k$ & $S W$ \\
\hline TMT-A & 31.00 & 22.0 & 0.12 & .170 & 30.0 & 16.0 & 0.37 & .496 & 30.50 & 17.0 & 0.94 & .052 \\
\hline TMT-B & 88.00 & 48.0 & 0.87 & .129 & 81.0 & 58.0 & 1.38 & .013 & 65.50 & 28.0 & 1.24 & .003 \\
\hline PM TA & 17.00 & 2.8 & -0.53 & .748 & 16.0 & 3.5 & -0.07 & .208 & 17.50 & 2.7 & 0.74 & .079 \\
\hline PM Q & 48.00 & 30.0 & 1.02 & .070 & 43.0 & 42.0 & 1.00 & .002 & 34.00 & 34.2 & 0.19 & .367 \\
\hline Stroop & 2.01 & 10.2 & 0.49 & .012 & 2.01 & 9.3 & -0.09 & .221 & 2.66 & 8.8 & 0.40 & .294 \\
\hline
\end{tabular}


Table 3 - Results of Kruskal-Wallis $H$ Test, Monte Carlo-Mann-Whitney $U$ Tests Post-hoc Pairwise Comparisons, and Cohen's $r$ for Executive Measures Performance primary $x$ recidivists $(n=44) \quad$ primary $x$ non-offenders $(n=55) \quad$ recidivists $x$ non-offenders $(n=49)$

$\begin{array}{llllllllllll}H & p & U & p(99 \% C I)^{I)} & r & U & p(99 \% C I)^{I)} & r & U & p(99 \% C I)^{I)} & r\end{array}$

$\begin{array}{llllllllllll}\text { TMT-A } & 1.348 & .510 & 192.0 & .284(.273-.296) & -.162 & 361.0 & .820(.810-.830) & -.031 & 283.5 & .347(.335-.360) & -.136\end{array}$

$\begin{array}{llllllllllll}\text { TMT-B } & 7.114 & .029 * & 201.0 & .392(.380-.405) & -.130 & 286.5 & .135(.126-.143) & -.201 & 151.0 & .005(.003-.007)^{* *} & -.393\end{array}$

$\begin{array}{llllllllllll}\text { PM TA } & 5.799 & .055 & 202.0 & .408(.396-.421) & -.127 & 235.0 & .016(.012-.019)^{*} & -.320 & 221.0 & .187(.177-.197) & -.188\end{array}$

$\begin{array}{llllllllllll}\text { PM Q } & 4.876 & .087 & 236.5 & .985(.982-.988) & -.003 & 264.0 & .062(.056-.069) & -.253 & 195.5 & .064(.058-.070) & -.262\end{array}$

$\begin{array}{lllllllllllll}\text { Stroop } & .170 & .919 & 227.5 & .819(.809-.829) & -.035 & 349.5 & .672(.660-.684) & -.058 & 283.5 & .981(.977-.984) & -.004\end{array}$

${ }^{1)}$ Monte Carlo-Mann-Whitney - based on 10000 sampled tables

$* \mathrm{p}<0,05 ; * * \mathrm{p}<0,01$ 